\title{
Analysis of the time spent on Facebook by Romanian university students
}

\author{
Iuliana Valentina Manea \\ Technical University of Civil Engineering \\ Splaiul Independentei 54, Bucharest, \\ Romania \\ m.valentinalyahoo.ro
}

\section{DOI: $10.37789 /$ rochi.2020.1.1.10}

\begin{abstract}
The use of Facebook by university students is a hot topic of research for more than ten years. However, few studies exist that are questioning the minutes spent daily for various tasks, such as socialization, posting/reading information, entertainment, and creation/update of the personal profile. Also, there are few studies investigating group differences as regards the various aspects of Facebook usage. This paper aims to analyze the differences by gender and year of study as regards the general characteristics of Facebook usage, motives for Facebook use, and time spent on Facebook for various activities. The results show that female students have larger Facebook networks and spend more time daily, especially for reading, posting, and sharing information. After the first year of study, students spend less time on entertainment and more time for editing the personal profile.
\end{abstract}

\section{Keywords}

Social networking websites, Facebook, university students.

\section{ACM Classification}

D.2.2: Design tools and techniques. H5.2 User interfaces.

\section{INTRODUCTION}

The popularity of Facebook among university students is continuously increasing. According to facebrands.ro, there were 9.6 million Romanian Facebook users by January 2017 out of which $21.47 \%$ were young users in the range 18-24 years. According to internetworldstats.com, the number of users in January 2020 was 10.86 million, 56.4\% penetration rate.

University students are using social networking websites for different reasons: knowing new people, maintaining social relationships, collaboration, socialization, finding various information and resources, and entertainment $[1,3$, $4,6,11,12]$. The daily use is spawned between a wide range of activities: chat, getting information and resources, finding out and sharing what is new, joining various groups of interest, promoting their image (personal profile), group work, and entertainment.

Although Facebook usage is an important research concern, few studies exist that are investigating the distribution of time spent daily for various tasks, such as socialization, posting/reading/sharing information, creation/update of the personal profile, and entertainment. Another issue is the analysis of group differences in Facebook usage. Since

\author{
Costin Pribeanu \\ Academy of Romanian Scientists \\ Str. Ilfov No.3, Bucharest, Romania \\ costin.pribeanudaosr.ro
}

Facebook is widely used by young people starting from the high-school, another research question is which differences exist between the first-year students (freshmen) and other students.

This paper aims to analyze the distribution of time spent on Facebook. The time is analyzed separately by gender and year of study (first-year students vs. other students). Secondary goals are to analyze group differences as regards the general characteristics of usage and the motives for Facebook use. The study is using a data sample of 182 university students.

The rest of this paper is organized as follows. In the next section, related work is discussed. The method, data sample, and variables are presented in section 3. In section 4, three analyses are presented, as regards the general characteristics of Facebook usage, the motives for Facebook use, and the distribution of time spent daily for various tasks. The paper ends with a conclusion in section 5.

\section{RELATED WORK}

The time spent on Facebook by university students has an important contribution to their personal development by enhancing their communication skills and making them more sociable. Social networking websites have a positive influence on the bridging social capital of students [9] by enlarging social horizons, better communication with university people, an increased sense of belonging and participation $[4,12]$.

The studies of Selwin [10] and Ellison et al. [4] found that Facebook has a positive influence on students' formation, integration, and participation in the university community. Valenzuela et al. [12] found a positive correlation between the intensity of Facebook use and students' life satisfaction and civic engagement.

Junco [8] analyzed the relationship between the frequency of Facebook use, participation in Facebook activities, and student engagement on a large sample of 2368 college students. The results show that time spent on Facebook is positively related to co-curricular activities and real-world involvement on campus. In a similar vein, Selwin [S09] found that Facebook stimulates critical thinking and creates an open space for informal education of students.

The study of Cheung et al. [3] investigated the motives for Facebook use by students. They adopted the social influence theory, social presence theory, and the uses and gratification paradigm to explain why students are using Facebook and found that social presence was the most 


\section{Proceedings of RoCHI 2020}

influential variable.

Yang and Bradford-Brown [11] analyzed the role played by social networking websites for the new students' adjustment to college. They found a positive correlation between social adjustment to college and using Facebook for maintaining social relationships. They also argued on the need to investigate specific activities rather than measuring the total time spent on social networking websites.

Chan et al. [2] explored the factors influencing user satisfaction in Facebook use and the moderating effect of gender on user satisfaction. They found that maintaining social relations and entertainment are the most important drivers of user satisfaction. While male students seemed to be more attracted by entertainment, female students were more interested in maintaining social relations.

Two previous studies explored general characteristics and motives for Facebook use on samples of Romanian university students. The former study [1], using a sample from a university of economics, found that the main motives for Facebook use were maintaining social relationships with high-school friends, socialization, and finding out what is new.

The latter study [6], using samples from two different universities, found that university students were using Facebook mainly for socialization, information, and collaboration purposes. An analysis of gender differences [5] showed that analyzed the time spent daily by university students from two universities and found that female students are more interested in maintaining social relations and less interested than male students in getting in touch with new people.

\section{METHOD}

The research questions are related to the differences by gender and the differences between first-year students and other studies as regards (1) general characteristics of Facebook usage, (2) motives for Facebook use, and (3) time spent on Facebook for various activities.

The data has been collected in May 2019 from a total of 182 students ( 127 males and 55 females) from the University of Building Engineering in Bucharest. The age of participants ranges between 18 and 34 years $(\mathrm{M}=20.36, \mathrm{SD}=2.00)$.

After answering some several general questions as regards age, gender, and year of study they have been asked to answer questions related to the characteristics of usage, as shown in Table 1.

\section{Table 1. Questions related to Facebook usage}

How many FB friends do you have in your FB network?

How many of your FB friends are students in this university?

On average, how many days per week do you use Facebook?

On average, how many times per day do you log on Facebook?

( $1=$ once, $2=$ twice, $3=$ three and more, $4=$ continuous $\log$ )

On average, how many minutes per day do you use Facebook?

Next, students have been asked to answer six questions related to the distribution of time spent daily on Facebook, by indicating the percentage. The questions are presented in Table 2 .
Table 2. Questions related to the distribution of time Which is the weight of time spent on FB for socialization? Which is the weight of time spent on FB for reading posts? Which is the weight of time spent on FB for posting and sharing posts?

Which is the weight of time spent on FB for entertainment? Which is the weight of time spent on FB for your Facebook profile?

Which is the weight of time spent on FB for other activities?

Then students have been asked to rate several statements on a 7-points Likert scale. The statements related to the motives for Facebook use are presented in Table 3.

Table 3. Motives for Facebook use

FBU1 I use Facebook to get in touch with new people

FBU2 I use Facebook to keep in touch with people I know

FBU3 I use Facebook to find information and resources

FBU4 I use Facebook for socialization purposes

FBU5 I use Facebook for collaboration purposes

FBU6 I use Facebook for entertainment purposes

Data analysis has been carried out using Lisrel 9.30 for Windows. The differences have been analyzed with oneway ANOVA.

\section{ANALYSIS BY GENDER}

\section{General characteristics of Facebook use}

The number of Facebook friends is large, varying from 6 to 5781 with a mean of $1173.13(\mathrm{SD}=1113.12)$. The number of Facebook friends from the university is varying from 2 to 500 with a mean of $61.17(\mathrm{SD}=72.65)$.

The frequency of use is measured by two variables: number of days/week and number of logs/day. The number of days/week is varying from 1 to $7(\mathrm{M}=5.54, \mathrm{SD}=2.10)$. The number of $\operatorname{logs} /$ day is varying from 1 to $4(\mathrm{M}=2.72$, $\mathrm{SD}=0.87)$. Most of the students $(72.5 \%)$ are logging on Facebook two or three times per day. The time spent daily on Facebook is varying between 3 and 400 minutes $(\mathrm{M}=60.85, \mathrm{SD}=68.69)$.

The characteristics of usage by gender are presented in Table 4.

Table 4. Characteristics of usage $(N=182)$

\begin{tabular}{|l|r|r|}
\hline Variable & \multicolumn{1}{|c|}{$\begin{array}{l}\text { Male } \\
(\mathrm{N}=127)\end{array}$} & $\begin{array}{l}\text { Female } \\
(\mathrm{N}=55)\end{array}$ \\
\hline Facebook friends & 1028.54 & 1507.00 \\
\hline Facebook friends students & 45.76 & 96.75 \\
\hline Days / week & 5.32 & 6.04 \\
\hline Logs / day & 2.67 & 2.84 \\
\hline Minutes / day & 54.61 & 75.27 \\
\hline
\end{tabular}

All variables have higher mean values in the case of female students. A one-way ANOVA $(1,180,181)$ showed that differences are statistically significant for Facebook friends $(\mathrm{F}=7.339, \mathrm{p}=0.007)$, Facebook friends studying in the same university $(\mathrm{F}=20.994, \mathrm{p}=0.000)$, and days/week $(\mathrm{F}=4.575$, $\mathrm{p}=0.034)$. The difference is marginally significant for the minutes spent daily $(\mathrm{F}=3.522, \mathrm{p}=0.062)$. 


\section{Proceedings of RoCHI 2020}

\section{Motives for Facebook use}

According to the mean values, the main motives for Facebook use are keeping in touch with known people, socialization, and entertainment. On the whole sample, only one item (getting in touch with new people) has a mean value below the neutral value (4.00 on a 7 -points Likert scale).

Table 5. Motives for Facebook use (mean values)

\begin{tabular}{|l|r|r|r|r|}
\hline \multirow{2}{*}{ Variable } & \multicolumn{2}{|c|}{ Total } & \multicolumn{1}{l|}{$\begin{array}{l}\text { Male } \\
(\mathrm{N}=127)\end{array}$} & \multicolumn{1}{l|}{$\begin{array}{l}\text { Female } \\
(\mathrm{N}=55)\end{array}$} \\
\cline { 2 - 5 } & $\mathrm{M}$ & $\mathrm{SD}$ & & 3.42 \\
\hline FBU1 & 3.54 & 1.59 & 3.59 & 6.25 \\
\hline FBU2 & 5.69 & 1.55 & 5.44 & 4.93 \\
\hline FBU3 & 4.23 & 1.75 & 3.92 & 5.51 \\
\hline FBU4 & 5.18 & 1.66 & 5.04 & 4.69 \\
\hline FBU5 & 4.16 & 1.76 & 3.94 & 5.36 \\
\hline FBU6 & 5.14 & 1.82 & 5.04 & \\
\hline
\end{tabular}

Comparison by gender shows large differences between the perception of male and female students. A one-way ANOVA (1, 180, 181) shows that these differences are statistically significant for FBU2 $(\mathrm{F}=11.215, \mathrm{p}=0.001)$, FBU3 ( $\mathrm{F}=13.631, \mathrm{p}=0.000)$, and FBU5 $(\mathrm{F}=7.308, \mathrm{p}=0.008)$ and marginally significant for FBU4 ( $F=3.120, \mathrm{p}=0.079)$.

Overall, female students rated higher all items, except for the first (getting in touch with new people).

\section{Distribution of time spent on Facebook}

For the whole sample, the most time-consuming task is socialization (chat) which accounts for $36 \%(\mathrm{SD}=0.26)$ from the total time. The next time slots are spent for entertainment $(\mathrm{M}=0.21, \mathrm{SD}=0.08)$, reading information $(\mathrm{M}=0.15, \mathrm{SD}=0.12)$, posting and sharing information $(\mathrm{M}=0.08, \mathrm{SD}=0.08)$, and updating the personal profile $(\mathrm{M}=0.08, \mathrm{SD}=0.08)$. Other activities account for $12 \%$ of the time $(\mathrm{SD}=0.11)$

The differences by gender as regards the distribution of time spent on Facebook is presented in Figure 2.

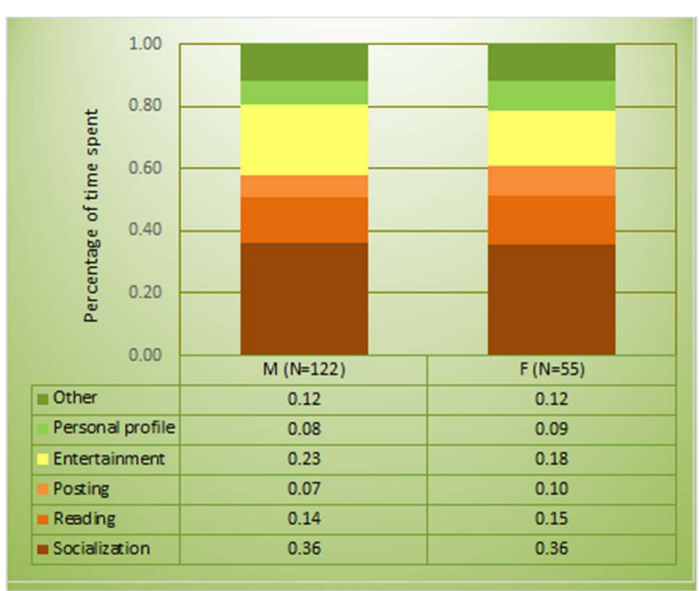

Figure 1. Distribution of time spent on Facebook

Male students are spending more time than female students for entertainment and less time for updating the personal, reading, and posting/sharing information. However, a oneway ANOVA $(1,180,181)$ shows that differences are marginally significant only for posting /sharing information $(\mathrm{F}=3.17, \mathrm{p}=0.077)$.

\section{ANALYSIS BY YEAR OF STUDY}

\section{General characteristics of Facebook use}

The gender differences as regards the characteristics of usage are presented in Table 6 (mean values).

.Table 6. Characteristics of usage $(\mathrm{N}=182)$

\begin{tabular}{|l|l|l|}
\hline Variable & $\begin{array}{l}1^{\text {st }}(\mathrm{Near} \\
(\mathrm{N}=122)\end{array}$ & $\begin{array}{l}\text { Other } \\
(\mathrm{N}=60)\end{array}$ \\
\hline Facebook friends & 1096.16 & 1329.63 \\
\hline Facebook friends students & 47.95 & 88.97 \\
\hline Days / week & 5.47 & 5.67 \\
\hline Logs / day & 2.73 & 2.72 \\
\hline Minutes / day & 59.79 & 63.02 \\
\hline
\end{tabular}

Almost all variables have lower mean values for the firstyear students. The number of Facebook friends that are students in the same university is much lower. A one-way ANOVA $(1,180,181)$ showed that only this difference is statistically significant $(\mathrm{F}=13.84, \mathrm{p}=0.000)$.

\section{Motives for Facebook use}

The differences as regards the motives for Facebook use are presented in Table 7 (mean values and standard deviation on total, mean values by year of study).

\begin{tabular}{|c|c|c|c|c|}
\hline \multirow[t]{2}{*}{ Variable } & \multicolumn{2}{|c|}{ Total } & \multirow{2}{*}{$\begin{array}{l}1^{\text {st }} \text {-year } \\
(\mathrm{N}=122)\end{array}$} & \multirow{2}{*}{$\begin{array}{l}\text { Other } \\
(\mathrm{N}=60)\end{array}$} \\
\hline & M & SD & & \\
\hline FBU1 & 3.54 & 1.59 & 3.51 & 3.60 \\
\hline FBU2 & 5.69 & 1.55 & 5.69 & 5.68 \\
\hline FBU3 & 4.23 & 1.75 & 4.17 & 4.33 \\
\hline FBU4 & 5.18 & 1.66 & 5.18 & 5.18 \\
\hline FBU5 & 4.16 & 1.76 & 3.98 & 4.53 \\
\hline FBU6 & 5.14 & 1.82 & 5.13 & 5.15 \\
\hline
\end{tabular}

A comparison between $1^{\text {st }}$-year students and other students shows similar mean values for three motives (FBU2, FBU4, and FBU5) and the same order of preferences. For the other three reasons, the mean values are lower for $1^{\text {st }}$-year students. A one-way ANOVA $(1,180,181)$ shows that the difference is statistically significant for FBU5 $(\mathrm{F}=4.00$, $\mathrm{p}=0.05$ ) which suggests that after the first year of study students are more interested to use Facebook for collaboration purposes.

\section{Distribution of time spent on Facebook}

The distribution of time spent on Facebook for various activities is different for $1^{\text {st }}$-year students, as shown in Figure 1 (mean values).

Freshmen are spending more time than other students for reading information and entertainment and less time for socialization, updating the personal profile, and posting /sharing information. This finding supports the idea that Facebook may play a positive role in students' adjustment to college. A one-way ANOVA $(1,180,181)$ shows that differences are marginally significant only for updating the personal profile $(\mathrm{F}=3.574, \mathrm{p}=0.060)$. 


\section{Proceedings of RoCHI 2020}

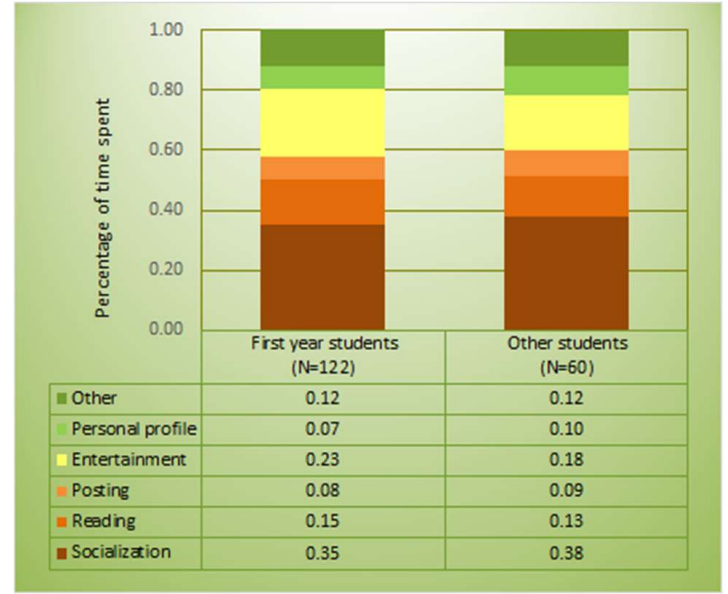

Figure 2. Distribution of time spent on Facebook

\section{Discussion}

The results of this study show that Romanian university students have a large Facebook network and spend a lot of time on Facebook. The main reasons for Facebook use are keeping in touch with known people (maintaining social relations), socialization, and entertainment. In this respect, the findings are similar to the results of other studies [3,11], as well as with the results of previous studies in Romania $[1,6]$.

The mean values of the variable measuring the motives for Facebook use are consistent with the distribution of time spent for these reasons. Socialization and entertainment account for more than $50 \%$ from the total time spent daily on Facebook by university students. As regards the time spent on entertainment, the findings confirm the previous results [7] showing higher mean values for first-year students.

As regards the gender differences, the findings confirm the results of other studies [5, 6]. Male students are more interested in entertainment than their female colleagues. Female students spend more time than male students for reading, posting, and sharing information on Facebook.

There are limitations of this exploratory study. First, given the cross-sectional nature of the study, it is not possible to measure the evolution in time of students' behavior. Second, the sample is relatively small and the number of $1^{\text {st }}$-year students is twice the number of other students. Last, but not least, as many authors pointed out [11, 12], the motives for Facebook use and the actual usage depend on a diversity of factors. Therefore, the conclusions of this study using a sample of college students from a particular university should not be generalized to other populations.

\section{CONCLUSION AND FUTURE WORK}

This study contributes to a better understanding of the time spent on Facebook by Romanian university students. The results show that socialization and entertainment are the main reasons why students are using Facebook and account together for more than half of the time spent daily on this social networking website.

Future work should continue in two research directions. The first direction is to enlarge the number of motives for Facebook use and refine the set of activities for the actual use. The second should be a longitudinal study to assess the evolution of time of Facebook-related behavior.

\section{REFERENCES}

1. Balog, A., Pribeanu, C. Ivan, I. (2015) Motives and characteristics of Facebook use by students from a Romanian university. In: Dardala, M., Rebedea, T.E. (Eds.) Proceedings of RoCHI 2015, Bucharest, 24-25 September, 137-140.

2. Chan, T. K., Cheung, C. M., Shi, N., \& Lee, M. K. (2015). Gender differences in satisfaction with Facebook users. Industrial Management \& Data Systems, 115(1), 182-206, https://doi.org/10.1108/IMDS-08-2014-0234

3. Cheung, K., Chiu, P.-Y., Lee, M. (2011) Online social networks: Why do students use Facebook. Computers in Human Behavior, 27(4), 1337-1343. https://doi.org/10.1016/j.chb.2010.07.028

4. Ellison, N.B., Steinfield, C., Lampe, C. (2007). The benefits of Facebook "Friends:" Social capital and college students' use of online social network sites, Journal of Computer-Mediated Communication 12, 1143-1168.

5. Iordache, D. D. (2017). Gender differences in the motives of using online social networks by university students. Proc. eLSE 2018, Vol. 2, 570-577. DOI:10.12753/2066-026X-17-166

6. Iordache, D. D., \& Pribeanu, C. (2016). Exploring the motives of using Facebook - a multidimensional approach. Revista Romana de Interactiune OmCalculator, 9(1), 19-34.

7. Iordache DD, Pribeanu C, Gorghiu G, Manea VI (2018) Distribution of time spent on Facebook by students from two Romanian universities. Proc. of IE 2018 Conference, Iasi 17-18 May, 195-200.

8. Junco, R. (2012). The relationship between frequency of Facebook use, participation in Facebook activities, and student engagement. Computers \& Education, 58(1), 162-171.

9. Putnam, R. D. (2000). Bowling Alone. New York: Simon \& Schuster.

10. Selwyn, N. (2009). Faceworking: exploring students' education-related use of Facebook. Learning, Media, and Technology 34(2), 157-174.

11. Yang, C. C., \& Brown, B. B. (2013). Motives for using Facebook, patterns of Facebook activities, and late adolescents' social adjustment to college. Journal of youth and adolescence, 42(3), 403-416. https://doi.org/10.1007/s10964-012-9836-x

12. Valenzuela, S., Park, N., \& Kee, K. F. (2009). Is There Social Capital in a Social Network Site?: Facebook Use and College Students' Life Satisfaction, Trust, and Participation. Journal of ComputerMediated Communication, 14(4), 875-901. 